\title{
$\mathrm{ICT}$ 를 이용한 생활 밀착형 디지털 컨버전스에 관한 연구 \\ 이성훈 \\ 백석대학교 정보통신학부
}

\section{A Study on Digital Convergence Related with Our Life using ICT}

\author{
Seong-Hoon Lee \\ Div. of Information Communication, Baekseok University ${ }^{*}$
}

요 약 2011년 정부에서는 “IT 융합 기술예측조사 2025”를 발표하였다. 본 조사보고서는 10개 ICT 산업군을 대상 으로 하였다. 디지털이라는 단어와 결합된 컨버전스는 정보통신 분야의 단위기술들의 융합을 통해 등장하는 새로운 제품이나 서비스를 일컫고 있다. 이러한 컨버전스 기술의 파급효과 및 컨버전스 사회의 현상들은 이미 경제, 사회, 문화등 사회의 전 부분에서 가시화되고 있다. 본 연구에서는 10 개 ICT 산업군 중에서 우리 생활과 밀접하게 연관되 어 있는 4개 산업군(IT-건설, IT-자동차, IT-섬유, IT-의료)에 대한 컨버전스 관련 내용들의 필요한 기술현황 및 전망 등을 기술하였다.

주제어 : 컨버전스, IT-건설, IT-자동차, IT-섬유, IT-의료

\begin{abstract}
In 2011, Government introduced "IT Convergence Technology Prediction Survey 2025". This report includes 10 ICT industries. Convergence was combined with a word 'digital'. Digital convergence means a service or new product which appeared through fusion of unit technologies in information and communication regions. The effects of convergence technologies and social phenomenons are visualized in overall regions of society such as economy, society, culture, etc. In this paper, we described a prospects and technologies needed in digital convergence environment. And we described IT-Building, IT-Car, IT-Medicine, IT-Textile which was related with our lives in today among 10 ICT industries.
\end{abstract}

Key Words : Convergence, IT-Building, IT-Car, IT-Textile, IT-Medicine

\section{1. 서론}

21세기 사회는 컨버전스(Convergence) 또는 디지털 컨버전스(Digital convergence)의 시대가 될 것이라고들 한다. 정보화 사회에서 디지털이라는 말과 결합된 컨버 전스는 정보통신 분야의 단위기술들의 융합 또는 수렴을
통해 등장하는 새로운 제품이나 서비스 또는 그런 경향 을 일컫는 시대어로 사용되고 있다[1].

이처럼 디지털 컨버전스라는 말이 일차적으로 다양한 정보통신기술과 미디어, 상품과 서비스들의 융합, 하드웨 어간 융합, 소프트웨어간 융합, 하드웨어와 소프트웨어의 융합, 인간과 기계의 융합, 가상공간과 물리공간의 융합
Received 16 October 2013, Revised 8 November 2013 Accepted 20 November 2013

Corresponding Author: Dong-Woo Lee(Woosong University) Email:dwlee@wsu.ac.kr

ISSN: $1738-1916$
(C) The Society of Digital Policy \& Management. All rights reserved. This is an open-access article distributed under the terms of the Creative Commons Attribution Non-Commercial License (http://creativecommons.otg/licenses/by-nc/3.0), which permits unrestricted non-commercial use, distribution, and reproduction in any medium, provided the original work is properly cited. 


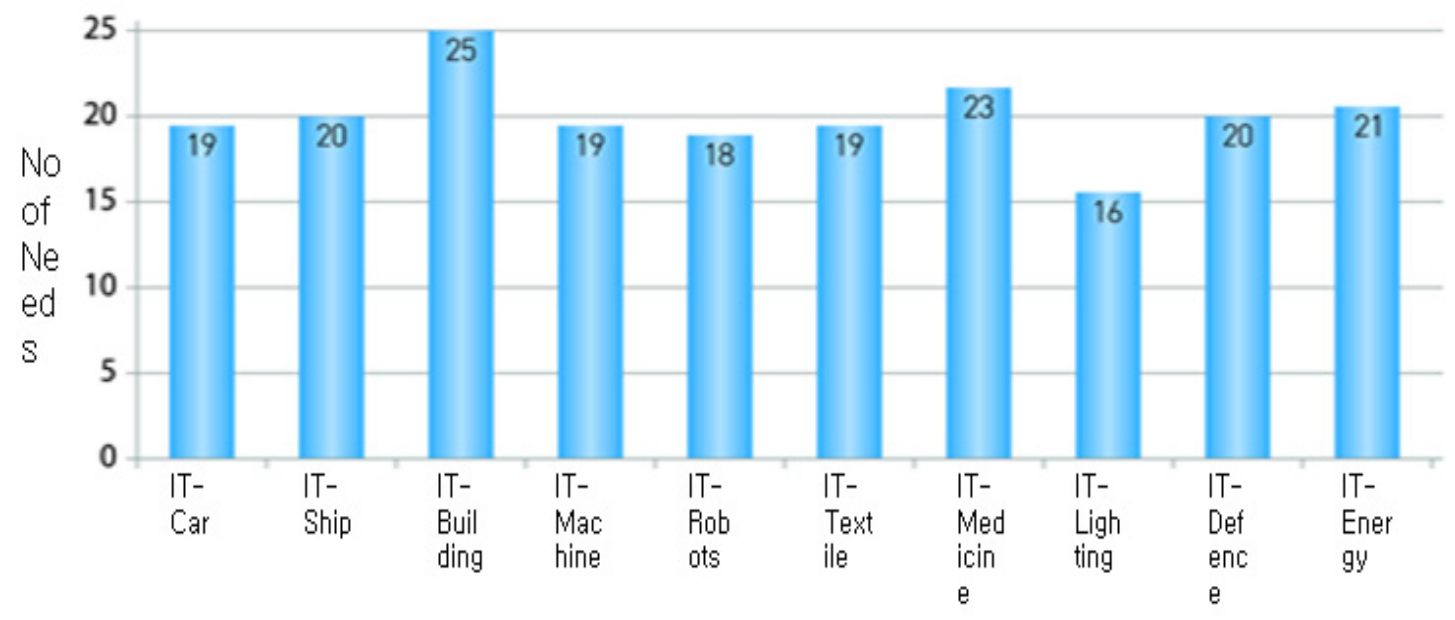

[Fig. 1] IT Convergence Technology Needs (출처:KEIT)

등으로 이해되지만 그 의미와 파장은 단순히 화학적 결 합이나 경제적 효용 증대에 머물지 않는다. 컨버전스 기 술의 파급효과와 새로운 컨버전스 사회의 전조는 이미 경제, 사회, 문화, 정치등 사회의 전 부분에서 가시화되고 있다[2]. 첨단 과학기술을 건설, 토목분야에 접목한 인텔 리전트 빌딩(Intelligent Building)과 스마트 하이웨이 (Smart Highway)등은 이미 현실화된 컨버전스의 사례 들이다. 과거 기계공학 분야의 전유물이었던 자동차 역 시 실제로는 기계공학, 전자공학, 재료공학과 디자인 분 야가 서로 힘을 합친 결과인데, 미래에는 친환경 기술, 인 간친화적인 기술들이 추가로 합류됨으로서 새로운 융합 자동차공학이 부상할 것이다.

디지털 컨버전스는 정보통신 기술을 기반으로 단위 기술들의 융합을 통해 새로운 제품이나 서비스를 창출하 는 것을 말한다. 이런 디지털 컨버전스는 과거에는 기술, 제품간의 단순한 기능적 결합이었지만, 최근에는 제품, 서비스간의 유기적 결합과 함께 기존 산업에 IT를 접목 해 산업 고도화와 신사업을 창출하고자 하는 방향으로 진화되고 있다. 궁극적으로는 기존 가치의 하락없이 새 로운 가치를 창출하고(Value Creation), 사업 및 서비스 영역을 확대하며(Convergence Extension), 기능을 하나 로 통합(Function Integration)하는 것을 지향한다고 볼 수 있다.

융합 환경을 구현하기 위해서는 서비스, 네트워크, 디 바이스(Device)등 3 개 요소가 필요하다. 서비스는 사용
자의 최종 사용 목적이고, 네트워크는 서비스를 가능하 게 하는 인프라적 요소이며 디바이스는 사용자가 서비스 와 네트워크에 연결될 수 있는 물리적 요소이다. 이러한 디지털 컨버전스를 위해 필요한 기술은 대략 4 가지 - 사 용자 인터페이스의 다양화, 증강현실 및 $\mathrm{SNS}$ (Social Network Service) 확산, M2M(Machine to Machine) 서 비스 확대, 실시간 유비쿼터스(Ubiquitous) 정보의 확대 - 로 나누어 볼 수 있다.

정부에서는 2011년 IT 기술과 연계된 컨버전스 산업 에 대한 기술 수요조사를 통해 [그림. 1]과 같이 10개 컨 버전스 산업에 대한 기술수요 수를 조사하였다[3]. 본 연 구에서는 이 중에서 우리의 생활과 직접적으로 매우 밀 접한 관계에 있으면서도 기술에 대한 수요 개수가 많은 4 개의 산업군에 대해 기술하였다.

\section{2. 생활 밀착형 디지털 컨버전스}

본 장에서는 우리 생활과 밀접하게 연관되어 있는 4 개 분야(IT-Car, IT-Building, IT-Textile, IT-Medicine)에 대한 디지털 컨버전스와 관련된 내용을 기술하였다.

\section{$2.1 \mathrm{IT}-\mathrm{Car}$}

최근 스마트 기술이 발전하면서 스마트 카. 즉 지능형 자동차로의 변신은 점차 현실화되고 있다. 현재의 고급 
차종을 보면 과거에서는 볼 수 없었던 똑똑한 기능들이 대거 현실로 등장하고 있다. 이처럼 기능의 스마트화 단 계를 거쳐 점차 새로운 가치와 문화를 창출할 수 있을 것 으로 전망되는 지능형 자동차의 미래는 다음과 같다.

먼저 자동차 본질의 기능에서는 주변상황을 실시간으 로 인식하는 다양한 센서와 자동 제어가 구현되는 지능 화된 제어시스템이 차량에 탑재되어 무인 자동 주차가 가능해지고 보행자 추돌 방지, 차량거리 자동제어, 사각 지역 위험감지 등으로 지능형 안전 주행이 가능해진다. 또한 주행중인 차량의 속도와 방향 제어와 차선 이탈 방 지가 지능화되어 자동 운전까지 진화할 수 있을 것으로 전망된다.

스마트 카는 본질적인 기능의 지능화뿐만 아니라 부 가적인 스마트 기능들이 실현되어 관리/운용/공간 등 다 양한 측면에서 새로운 가치 창출이 가능해질 것이다. 먼 저, 차량 내부 구성요소들에 대한 센싱과 제어가 가능한 기술과 스마트폰의 등장으로 본격화된 모바일 기술의 성 장은 스마트 폰을 비롯한 다양한 모바일 기기를 통해 원 격에서 차량 상태를 점검해 $\mathrm{A} / \mathrm{S}$ 와 긴급 콜 서비스까지 연계되고 실시간 위치 추적을 통해 주차위치 안내와 도 난 추적이 가능해진다. 또한, 기존 차량 키의 기능을 스마 트폰을 통해 무선으로 원격에서 도어와 시동을 제어할 수 있다. 또 다른 스마트 카의 대표적인 특징으로는 인포 테인먼트를 들 수 있다. 여기에서는 미래 지향형 인포테 인먼트의 모습 중에 대표적인 3가지를 기술한다.

먼저, 증강현실 네비게이션이다. 교통상황, 사고 등 다 양한 교통정보와 위치정보를 실시간으로 센싱하고 이를 지능적으로 분석하여 목적지까지의 최적의 경로를 도출 한다. 이렇게 도출된 정보를 기존 별도의 기기가 아닌 차 의 앞 유리를 통해 보이는 실제 외부 환경과 결합된 증강 현실 기반의 실감적이고 정확한 내비게이션 서비스를 제 공해 운전자의 편의성을 향상시킬 수 있다.

둘째로 인포머티브로서 인포머티브가 유익한 정보를 제공한다는 의미인 것처럼 차량 위치에 따라 전기 충전 소, 공용 주차장, 공원 등과 같이 주변정보를 실시간으로 센싱하고 이를 탑승자의 관심사, 목적 등에 따라 분석 및 커스터마이징하여 맞춤형 정보를 생성한다. 그리고 이러 한 정보도 차량 앞 유리에 증강현실과 GIS가 결합하여 제 공함으로써 이용자는 유익한 정보 기반 편의성과 의사결 정의 최적화를 통해 현명한 가치를 체감할 수 있게 된다.
마지막으로 차량 내부에서 새로운 개념의 엔터테인먼 트가 가능해진다. 차량에 탑재된 태블릿 $\mathrm{PC}$ 나 이용자가 소유한 스마트폰을 통해 영화, 음악, 게임 등과 같은 다양 한 콘텐츠를 실시간으로 다운로드 받을 수 있게 되고, 이 를 기반으로 차량 내부에서 다양한 엔터테인먼트를 즐길 수 있게 될 것이다. 대표적인 예로 차량에서 영화를 선택 하게 되면 내부는 영화관 같은 어두운 분위기가 자동으 로 조성되고 차량 앞 유리는 영화관의 스크린과 같은 기 능으로 자동 전환되어 모바일 영화관으로서의 새로운 공 간이 탄생한다.

이처럼 향후 스마트 카는 단순히 지능형 주행으로서 의 발전과 더불어 모바일 오피스, 모바일 카페 등 새로운 가치와 문화를 창출하는 공간으로도 진화 성장할 것으로 전망된다.

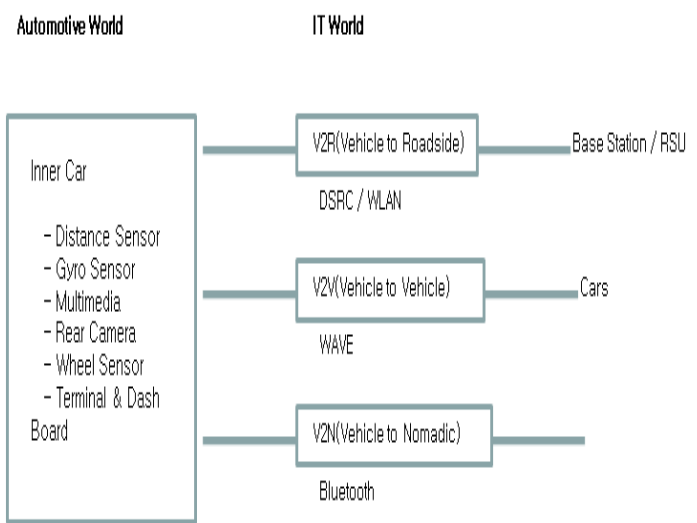

[Fig. 2] IT-Car

\subsection{IT-Building}

IT-건설에 대한 디지털 컨버전스는 대표적으로 스마 트 시티로 대변될 수 있다. 이러한 스마트 시티는 첨단 정보통신 기술을 이용해 주요 도시의 공공기능을 네트워 크화한 도시를 의미한다. 이를 위해 센서 중심의 유비쿼 터스 환경에 지능화의 의미가 포함된 도시를 말한다 [1][4]. 이러한 스마트 시티의 배경으로는 크게 3가지를 열거할 수 있다.

첫째, 도시화의 가속화 현상을 들 수 있다. 2000년 이 후 도시거주 인구수는 교외지역 인구수보다 많아졌으며, 이로 인해 UN에서는 도시화에 수반되는 문제들에 대한 관심, 해결책등의 필요성을 지적하면서 2000년에 Urban 
Millennium을 선언하게 되었다.

2030년 이후에는 전체 인구 약 81 억명 중 50 억 명이 도시에 거주할 것으로 예상하였다. 또한 도시의 개수가 증가하고 도시 거대화 현상이 두드러지게 출현할 것으로 예측했다[7].

둘째로 생활 패턴의 변화를 들 수 있다. 현대 사화가 산업화 사회를 거치면서 경제적 여유로움으로 삶의 질을 추구하는 경향이며, 고령화 사회를 맞아 건강 및 환경 친 화적인 요소를 중요시 하고 있다. 또한 도시내에서의 자 족 기능 필요성이 증대되고 있다.

마지막으로 IT 융합 현상을 들 수 있다. IT 관련 기술 들이 발전하면서 타 산업과의 컨버전스 현상이 다양한 분야에서, 또한 새로운 영역 형태로 등장하고 있는 것이 다. 스마트 시티는 초기, 인터넷 기반의 컴퓨터안에서의 사이버 시티(Cyber city)로부터 시작하여, 현재의 스마트 시티로 발전되어 오고 있다.

스마트 시티에 대한 프레임워크는 [그림 3]에서처럼 5 개 요소로 구성되어 있으며, 각 구성요소별 내용은 다음 과 같다.

스마트 정부(Smart Government)에서는 도시민들이 필요한 서비스를 제공하며, 다양한 인프라들을 관리, 감 독하는 기관을 의미한다. 스마트 빌딩(Smart Building)이 란 냉난방, 조명, 전력시스템을 통해 운영이 자동화된 빌 딩으로 미국의 OCS(Office Communication System)을 들 수 있다. 미국의 최초 스마트 빌딩으로는 시티플레이 스 빌딩을 일컫는다. 스마트 모빌리티(Smart Mobility)는 스마트 기술과 융합된 보다 똑똑해진 미래 교통서비스의 총체적 개념으로서, 개인 및 사회 맞춤형 서비스로 분류 할 수 있다. 개인 서비스는 이용자의 특성 및 상황에 맞 는 상황 맞춤형 서비스를 제공하며, 사회 서비스는 교통 관리 측면에서 교통흐름 및 수요를 최적화하는 것을 의 미한다. 스마트 에너지 및 환경에서 스마트 에너지는 스 마트 그리드를 의미하며, 스마트 환경은 자연친화적인 요소들 즉, 그린 IT 및 저탄소 정책등을 의미한다. 스마 트 서비스(Smart Service)는 시민들에게 제공하기 위한 다양한 서비스 유형들을 의미하며, IT기기등을 통해 수 집, 가공한 활용 가능한 서비스를 말한다. 여기에는 행정, 보건, 환경, 방범, 교육, 문화등의 각종 서비스들이 포함 된다.

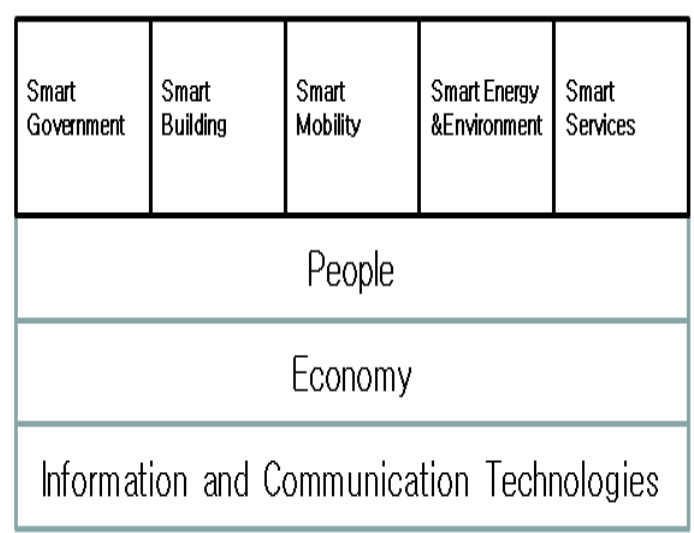

[Fig. 3] Smart City Framework in IT-Building

\subsection{IT-Textile}

IT-섬유에 대한 컨버전스의 형태는 웨어러블 컴퓨팅 형태로 나타낼 수 있다. 웨어러블 컴퓨터(Wearable Computer)는 문자 그대로 “입는 컴퓨터”로서, 사람의 몸 에 착용하여 다양한 정보들이 통합 처리되어 사용자의 인지능력, 문제해결 능력등을 증대시키는 장치라 할 수 있다[7][8][9]. 세상에 처음으로 등장한 웨어러블 컴퓨터 는 1966년에 MIT 대학교에서 발표한 $\mathrm{HMD}(\mathrm{Head}$ Mounted Display)이다. 하지만 현재 웨어러블 컴퓨팅이 라 불리는 테크(Tech)의 방향을 정의한 것은 1981년 스 티브 만(Steve Mann)이 개발한 배낭형 컴퓨터이다.

웨어러블 컴퓨터는 착용형 혹은 의복형태의 개인용 컴퓨터를 말하며, 초기에는 양손을 자유롭게 사용하면서 작업 매뉴얼을 봐야하는 비행기 정비사를 위해 개발되었 지만 의료분야, 제조 및 물류분야, 군수장비, 교육 및 훈 련분야등으로 응용 범위가 점점 확대되고 있다 [10][11][12].

일반 사용자를 위한 범용의 웨어러블 컴퓨터는 우리 가 일반적으로 입고 다니는 옷이나 액세서리 같은 형태 로 자연스럽게 착용할 수 있어야 하며, 사용자의 요구에 즉각 반응해야 한다. 또한 기기 사용에 따른 안정성을 보 장해야 하고, 착용에 따른 문화적 이질감을 극복할 수 있 어야 한다. 또한 장치를 사용하는 것 보다는 장치와 융합 할 수 있는 사용자 인터페이스 기능을 지원해야 한다. 이 러한 기능을 구현하기 위한 웨어러블 컴퓨터 기술로는 하드웨어 플랫폼 기술, 사용자 인터페이스 기술, 상황인 지 기술, 저전력 기술, 근거리 통신기술등이 포함된다. 
초기의 웨어러블 컴퓨터 기술은 기존의 컴퓨터를 모 듈별로 분해해서 사용자의 몸에 적절히 분산시키는 수준 의 개념적 구현에 그쳤으나, 최근에는 전자부품의 획기 적 발전으로 초소형, 저전력 플랫폼 설계가 가능하게 되 었으며 따라서 액세서리 같은 신체 착용형과 의복형태의 시스템이 개발되고 있다. 웨어러블 컴퓨팅 기술은 요소 기술면에서 모바일 컴퓨터와 공통점이 많지만 하드웨어 플랫폼 및 사용자 인터페이스 기술에서 차별화가 두드러 진다.

웨어러블 컴퓨팅 플랫폼은 하드웨어 인프라를 지원하 는 하드웨어 플랫폼, 운영체제, 데이터베이스를 비롯한 소프트웨어 플랫폼, 디지털 의류 개발자 지원 개발 플랫 폼, 사용자지원 사용자 플랫폼등으로 구분하여 하부층으 로부터 상부층까지 구조를 형성한다.

웨어러블 컴퓨팅 하드웨어 플랫폼은 디지털의류 정 보서비스 지원을 위한 스토리지 및 메모리, 네트워크, 서버/PC, 의류센싱 및 외부환경센싱 디바이스, 웨어러 블 I/O 디바이스를 구성한다. 또한 확장 하드웨어플랫 폼으로 범용 스마트디바이스로 스마트폰, 스마트패드 등이 지원된다.

웨어러블 소프트웨어 플랫폼은 디지털의류의 컴퓨팅 서비스를 지원하기 위한 OS, FS(file system), 표준디바 이스 드라이버, 통신프로토콜, DBMS 등을 구성한다.

개발 플랫폼은 개발자를 지원하기 위한 개발라이브러 리, API, 프레임워크와 같은 개발도구, 컴파일러, 에디터, 디자인도구 등을 구성한다.

사용자 플랫폼은 사용자 기능요구사항을 조사하고, 사 용자인터페이스 및 사용자시나리오를 설계하기 위한 각 종 모델 및 도구들이 지원된다. 대부분의 웨어러블 컴퓨 터는 벨트/머리 착용형, 손목/팔 착용형, 의류기반형과 같은 콤펙터로 개발되고 있다.

\subsection{IT-Medicine}

$\mathrm{u}$-헬스케어는 정보통신기술들중에서 유비쿼터스 컴 퓨팅 개념을 보건의료산업에 접목함으로서 인체의 건강 관련 정보를 언제, 어디서나 수집, 처리, 전달, 관리 할 수 있게 함으로서, 제공되는 건강관리 및 의료서비스를 말 한다.

$\mathrm{u}^{\mathrm{u}}$ 헬스케어 서비스가 등장하게 된 배경으로는 첫째, 고령화 사회로의 진입현상이 가속화되고 있다는 점이다
[5][6]. 현재 우리사회는 이미 지난 2000년 65세 이상의 노인인구가 $7.2 \%$ 에 달하며, 고령화 사회로의 진입을 예 고했다. 지금과 같은 추세라면 2020년에는 노령인구가 무려 15\%를 상회하면서 안전한 완전한 고령사회(고령사 회, 65 세 이상 인구 $14 \%$ 이상) 가 된다고 한다. 이같은 추 이는 $\mathrm{OECD}$ 국가 중에서 가장 빠른 추세를 보이고 있다 [6].

둘째로, 의료비 지출의 증가추세를 들 수 있다. 인구 고령화와 만성질환자의 증가로 인하여 의료비 부담이 사 회 전체적으로 큰 부담으로 작용하고 있다. 최근의 환자 중 당뇨 및 고혈압 환자의 수는 생활환경의 변화등에 따 라 급증하고 있는 것으로 나타나고 있다. 이같은 추세를 반영하듯 우리나라의 연평균 1 인당 의료비는 $\mathrm{OECD}$ 평균 을 상회하는 지출 현상을 보이고 있다.

IT 융복합의 형태로 나타난 $\mathrm{u}$-헬스케어서비스는 그동 안 여러 개념들이 적용되면서 현재에 이르고 있다.

U- 헬스케어서비스의 모델은 크게 의료기관 중심의 $\mathrm{u}$-헬스모델로 의료기관의 내부 또는 의료기관 간에 진료 업무의 효율화를 증대시키기 위한 서비스 모델이며, 이 용자 중심의 $\mathrm{u}$-헬스모델(홈 헬스케어)은 의료기관 외부 의 이용자와 의료진을 연결하여 진료의 효율화를 증대시 키기 위한 서비스모델이 있다.

이중 이용자 중심의 $\mathrm{U}$-헬스케어시스템의 주요 역할 은 주로 만성질환자 또는 건강 위험자를 대상으로 의료 진의 적절한 개입(Intervention)과 이를 수행하고 만성질 환자 또는 건강위험자의 충실한 이행도(Compliance)를 향상하도록 정보를 제공하는데 주요 목적을 둔다.

$\mathrm{U}$-헬스케어서비스 시스템 구성 요소는 디바이스, 솔 루션, 통신망, IT서비스가 유기적으로 협업하는 융합시 스템 구성이 필요하여 관련 산업의 동반 성장이 기대되 고 있다. 그 예로 글로벌 홈 헬스케어 시장은 2013년 US 15억 달러 규모로 성장을 예상하고 있고, 현재는 모니터 링 디바이스가 주요 상품인 시장구조이다.

앞서 기술한 우리의 주변상황뿐만 아니라, U-헬스케 어서비스 성장요인으로는 전 세계 고령인구 증가(65세 이상 - 2009년 약 5억 명 $\rightarrow 2030$ 년 약 10 억 명)가 예상되 고 이에 동반한 만성질환 증가, 질병예방에 대한 관심으 로 앞으로도 폭발적인 성장을 할 것으로 전망되고 있다. 이에 따라 보다 다양하고 유기적인 시스템이 개발되면서 $\mathrm{U}$-헬스케어서비스도 세분화되고 다양화 되어 우리나라 
의 U-헬스케어서비스 산업은 10 년 후면 4 배 가까이 성장 할 것이라는 전망이다. U-헬스케어서비스 구성요소는 [그림 4]와 같다.

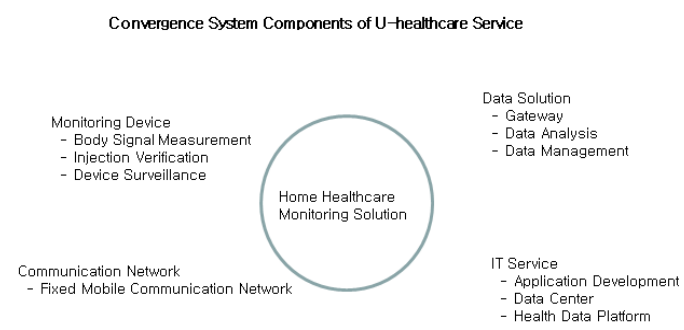

[Fig. 4] Components of U-healthcare Service

\section{3. 결론}

오늘날 우리는 “디지털 컨버전스”라는 이름으로 진행 되고 있는 디지털 세계의 수많은 세대교체 현상에 직면 하고 있다. 애플의 스마트폰 등으로 촉발된 스마트폰 경 쟁이 그러하다. 이로 인해 구글은 구글폰을 내놓더니, 이 제는 TV 영역에서 기존의 TV제조업체들을 긴장시키고 있다. 애플은 컴퓨터 하드웨어가 주 사업이었으며, 구글 은 네트워크 기반의 소프트웨어를 주로 다루었다. 하지 만 이들은 정보통신 영역인 이동통신 단말기 시장에 진 입을 시도하였고, 이러한 시장 진입 영역이 점점 더 확장 되고 있다. 바로 디지털 컨버전스의 대표적인 사례라 할 수 있다. 정부에서는 2011년에 "IT 융합 기술예측조사 2025 ”를 발표하였다. 보고서에는 10 개 산업군들에서 ICT 를 활용하기 위해 각 산업군에서 필요로 하는 기술들을 조사/분석하였다. 본 연구에서는 10 개 산업군 중에서 우 리 생활과 밀접한 관계에 있는 4 개의 산업군에서의 컨버 전스에 관한 내용들을 다루었다.

\section{REFERENCES}

[1] NIA, IT Based Industrial Convergence and Strategy Direction for National Information Society, 2010.

[2] LG CNS, Smart Technology. 2010.

[3] KEIT, IT Convergence Technology Prediction Survey 2025, 2011.
[4] NIA, "Future City through Smart City", IT\&Future Strategy, 2010.

[5] IDG Korea. 2012.

[6] Park Jung Hoon, Hwang Bo Taek Gyen, IT Convergence Healthcare Technology, KICS Magazine, May, pp. 21-27, 2011.

[7] OECD, Healthdata 2010, Mckinsey Global Institute, 2008.

[8] Hwang Hee Jung, Choi Jin Tak, Application framework for mutual operation improvement of U-health service, Korea IT Technology Academy Paper, KIIT, vol.8, no. 5, pp. 111-118, 2010.

[9] Kim NaMsub, “An Efficient Methodology of Fall Detection for Ubiquitous Healthcare, Korea IT Technology Academy Paper, KIIT, vol.8, no. 8, pp. 133-140, 2010.

[10] TaeGyu Lee, GiSoo Jung, SeongHoon Lee, "Textile IT Convergence”, Korea Institute of Information Technology Magazine, Vol. 10, No.2, pp. 77-86, 2012.

[11] YoungGi Son, JiYen Kim, IlYeon Cho, "Wearable Computer Technology and Development Trends", Electronic Communication Trend Analysis, Vol. 23, No. 5, 2008.

[12] IMS Research, "Wearable Technology Market Suited for Rapid Growth”, Press release. 2012.

이 성 훈

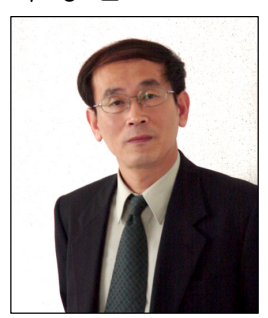

- 1998년 2월 : 고려대학교 컴퓨터학 과 (이학박사)

- 1998년 3월 현재 : 백석대학교 정 보통신학부 교수.

- 관심분야 : 분산 시스템, 무선 통신, 유전 정보. 웹서비스

• E-Mail : shlee@bu.ac.kr 